\title{
PREDATION AS A FACTOR INFLUENCING THE OCCURRENCE AND DISTRIBUTION OF SMALL CRUSTACEA IN WEST INDIAN GROUNDWATERS
}

\author{
by \\ JAN H. STOCK \\ Institute of Taxonomic Zoology, University of Amsterdam, \\ P.O. Box 20125, 1000 HC Amsterdam, The Netherlands
}

\begin{abstract}
SUMMARY
Hadziid Amphipoda are known from inland groundwaters of 14 West Indian islands, Thermosbaenacea from those of 9 islands. Only 4 islands show joint occurrence of both groups. Even in islands of joint occurrence, hadziids occur significantly more often alone in a given locality, than in combination with Thermosbaenacea or Copepoda Cyclopidae. The latter two groups do not show any significant avoidance of each other. Some possible causes for the non-random occurrence of small groundwater Crustacea are discussed; it seems most likely that hadziids predate on other Crustacea, such as Thermosbaenacea or Cyclopidae. This predation may have, or have had, influence on the actual distribution patterns of the groups under consideration.
\end{abstract}

\section{RÉSUMÉ}

Des Amphipodes Hadziides sont connus des eaux souterraines intérieures de 14 îles des Antilles; des Thermosbaenacés sont connus de 9 îles. C'est seulement sur 4 îles que les deux groupes se rencontrent; mais même dans ces dernières îles, il est nettement plus fréquent de trouver les Hadziides seuls à une certaine localité, qu'en association avec des Thermosbaenacés ou avec des Copépodes Cyclopidés (tandis que ces deux derniers groupes ne s'évitent pas de façon significative). On discute sur plusieurs raisons possibles du fait que la distribution de ces Crustacés souterrains de taille réduite présente ce caractère "non-random»; l'idée la plus plausible est que les Hadziides sont des prédateurs aux dépens de Crustacés tels que les Thermosbaenacés et les Cyclopidés. Ceci peut avoir - ou avoir eu - une influence sur la distribution actuelle de ces groupes.

*) Report 27 has been published in Bijdragen tot de Dierkunde, 53 (1): 165-177 (1983).

\section{INTRODUCTION}

During groundwater explorations (1800 stations in 43 islands) in the West Indies, great numbers of hypogean animals were encountered (see previous reports in this series). The most frequently represented groups were Oligochaeta, Gastropoda, and four crustacean taxa: Ostracoda, cyclopid Copepoda, Amphipoda, and Thermosbaenacea.

Groundwaters (in wells, springs, caves, river and beach interstitia) of the following islands have been investigated (fig. 1) during a ten years' period (1973-1982) by the Amsterdam Expeditions: Aruba, Curaçao, Bonaire, Islas Los Roques, La Tortuga, La Blanquilla, Los Testigos, Margarita, Barbados, St. Lucia, Martinique, Dominica, Guadeloupe, Antigua, Barbuda, St. Eustatius, Saba, St. Barthélémy, St. Martin, Tintamarre, Anguilla, Anegada, Virgin Gorda, Tortola, St. John, St. Thomas, St. Croix, Vieques, Culebra, Puerto Rico, Mona, Hispaniola (Haiti), Jamaica, Grand Cayman, Cayman Brac, South Caicos, Providenciales, Great Inagua, Mayaguana, Crooked Island, San Salvador Island, Eleuthera, and New Providence.

The present paper will discuss the occurrence and distribution of three crustacean groups, viz. the family Cyclopidae of the Copepoda, the hadziid group of the Amphipoda Gammaridae, and the order Thermosbaenacea, in inland groundwaters. Of these the cyclopids are encountered almost on every island, but hadziid 


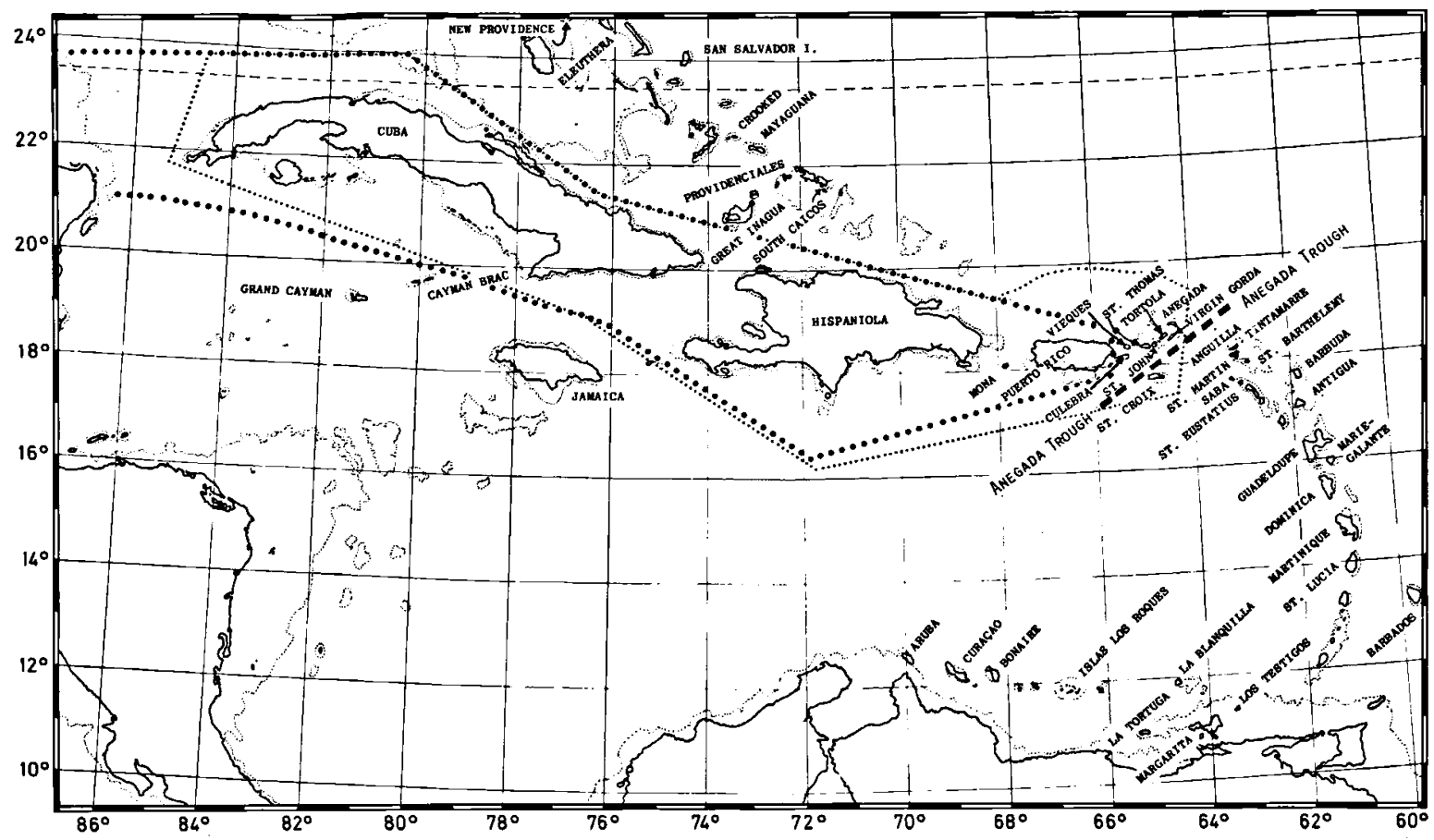

Fig. 1. Map of the West Indies, showing the islands mentioned in the text ( $\$ 1$ ). Heavy dots: Boundary of the distribution area of the generically diversified fauna of hadziid Amphipoda. Light dots: Boundary of the distribution area of the Thermosbaenacea. Heavy strokes: Position of the Anegada Trough.

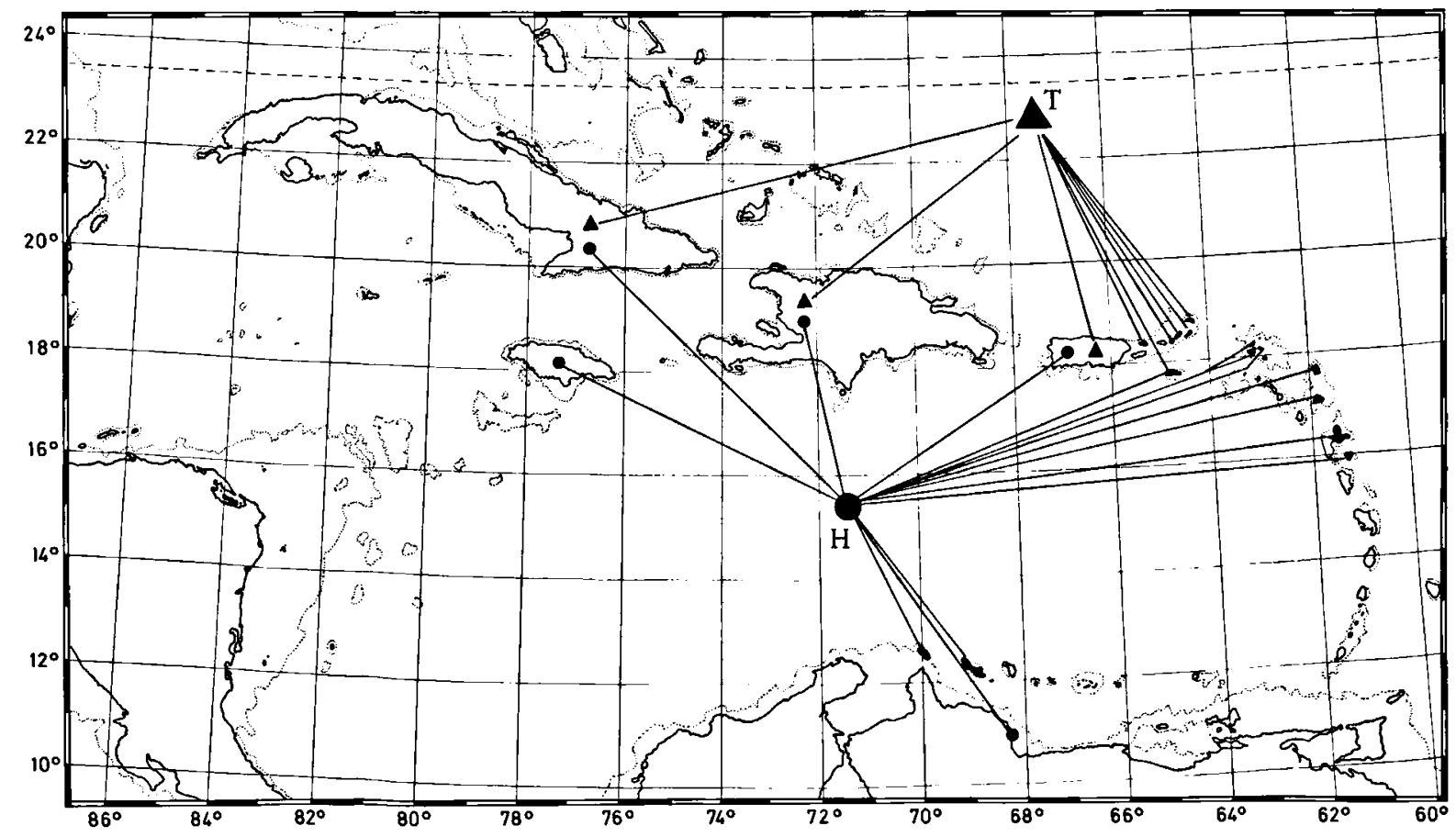

Fig. 2. Distribution of hadziid Amphipoda (H, black dots) and Thermosbaenacea ( $T$, triangles) in the West Indies. 
amphipods are restricted to certain calcareous islands (Stock, 1977, and more recent data of our own), viz. Aruba, Curaçao, GuadeloupeGrande Terre, Antigua, Barbuda, St. Martin, Tintamarre, Anguilla, St. Croix, Puerto Rico, Hispaniola, and Jamaica (fig. 2). Members of the hadziid group are also known from MarieGalante (Stock, 1980) and Cuba (Dancau, 1973; Holsinger, 1977), not visited during our investigations. Besides, marine or anchihaline hadziids, not considered in this paper, are known from certains islands in the Leeward group (Bonaire, Curaçao, La Tortuga), in the Bahamas, and from Puerto Rico.

Thermosbaenacea are more limited in their distribution. They have been found in the inland waters of nine islands, viz. St. Croix (Stock, 1976), Cuba (Botosaneanu et al., 1973: 14; Orghidan, 1973: 38) ${ }^{1}$ ), Anegada, Virgin Gorda, Tortola, St. John, Culebra, Puerto Rico, and Hispaniola (our own records). Moreover, marine or anchihaline thermosbaenaceans, not considered in this paper, are known from Curaçao (Stock, 1976, and unpublished data).

During the fieldwork it looked as if the three crustacean groups under consideration were, although not entirely mutually exclusive, only rarely found in each other's presence. For the combination hadziids - thermosbaenaceans this is already clear from the above enumeration of localities: the former have been found on 14 islands, the latter on 9 islands, but only 4 islands (Cuba, Hispaniola, Puerto Rico, and St. Croix) have both groups represented in their groundwaters (fig. 2).

The question whether or not the absence of the one group of crustaceans, and the simultaneous presence of the other is statistically significant, is examined in detail in the present paper. Possible causes for the observed distribution patterns are also discussed.

A shortened and preliminary draft of this paper has been presented as a congress lecture

1) Thermosbaenacea appear to be more common in Cuba than these single records in the literature suggest (Delamare Deboutteville, in litt., 1977). for the 3rd International Symposium of Groundwater Ecology (Lodz/Chestochowa, 1981), which was published recently (Stock, 1982). In the present paper, the data based on the completely sorted samples of the 1973 through 1982 campaigns are included, and several provisional results of the earlier draft have been put now in a more definite shape.

\section{ACKNOWLEDGEMENTS}

The fieldwork in the various West Indian islands has been made possible by grants of the Netherlands Foundation for the Advancement of Tropical Research (WOTRO), The Hague; the Treub Maatschappij, Utrecht; the Beijerinck Popping Fonds, Amsterdam, the Fonds Landbouw Hogeschool, Wageningen, and the Amsterdamse Universiteitsvereniging, Amsterdam.

The sampling has been executed by a team of changing composition, consisting of Lazare Botosaneanu, Nico Broodbakker, Sylvia van Lieshout, Jos Notenboom, Jan Stock, Maarten Stock, Steven Weinberg, and Francisca Zijlstra.

Many persons on the various islands, too many to be mentioned individually, helped us in various ways: by granting permissions, by providing transportation or accomodation, by guiding us to caves and wells, etc.

\section{MATERIAL AND METHODS}

Most samples have been collected with a vertical closing net of the Cvetkov type (see Bou, 1975), or with biophreatical pumps (Bou, 1975; Mittelberg, 1980). The entire sample was preserved in formalin $4 \%$ and sorted later in the laboratory under a dissecting microscope.

Chlorinities have been measured with an EEL electric chlorinimeter, or according to the ASTM method D512.

In the present paper the term "hadziids" is applied to a group of strictly stygobiont Amphipoda of the family Gammaridae, essentially the genera treated by Stock (1977) and Bousfield (1977), or by Barnard \& Karaman (1982) under the name "Hadziids and Weckeliids". Only the inland-water genera are considered (thus excluding the anchihaline or hypersaline genus Saliweckelia or the marine genus Protohadzia).

The hadziids are particularly rich in species in the Neotropics. On the Lesser Antilles, only one genus is present, Metaniphargus, with endemics on a number of islands. On the Greater Antilles several other genera, in addition to Metaniphargus, are known (see for an enumeration Stock, in Botosaneanu, in press).

The thermosbaenaceans of the West Indian inland waters comprise uniquely Monodella-like forms. The 
marine to anchihaline genus Halosbaena has not been considered. The entire group is stygobiont.

The Cyclopidae comprise a large number of genera and subgenera, some of them strictly stygobiont, others also known from epigean waters.

\section{STATISTICAL METHODS}

\subsection{Test}

The presence or absence of $n$ taxa $(1,2 \ldots \ldots m$, $n$ ) on $k$ different islands is compared. A test for scores on one variable for $k$ categories, essentially a $\chi^{2}$ test (Meddis, 1975: 60) is appropriate.

\subsection{Observed values $(O)$}

The observed frequencies of solitary occurrence of each taxon $\left(O_{1} \ldots \ldots O_{n}\right)$ are recorded in unrelated pairs $\left(O_{1}\right.$ with $O_{2} \ldots \ldots O_{m}$ with $\left.O_{n}\right)$ along with the observed frequency of the samples containing two taxa at a time $\left(O_{m+n}\right)$. The total number of positive stations (i.e., stations yielding any of the taxa studied) observed per category ( = island) is expressed by $S_{O}=O_{m}$ $+O_{n}+O_{m+n}$. Negative stations, containing none of the taxa studied, are not considered.

The number of scores observed per category, $N_{O}$, is $O_{m}+O_{n}+2 O_{m+n}$. This may not seem obvious, but can be understood if one bears in mind that taxon $m$ occurs at $O_{m}$ stations alone, and at $O_{m+n}$ stations together with taxon $n$, whereas taxon $n$ occurs at $O_{n}$ stations alone and at $O_{m+n}$ stations jointly with taxon $m$. The total number of scores for taxa $m$ and $n$ is thus $O_{m}+$ $O_{m+n}+O_{n}+O_{m+n}=O_{m}+O_{n}+2 O_{m+n}$. The total number of scores for all islands, the $N$ of the $\chi^{2}$ test, is $\Sigma N_{O}$.

\subsection{Expected values}

The expected frequency of joint occurrence $\left(e_{m+n}\right)$ of taxa $m$ and $n$, calculated on the basis of the separate occurrence of $m$ and $n$ on each island, can be estimated as follows:

If one supposes that the observed frequencies of the taxa $m$ and $n$ per island are realistic, although they may deviate from a random and even pattern, one can calculate the expected number of joint occurrence. The taxon $m$ is present in a fraction of the stations sampled, this fraction being $\left(O_{m}+O_{m+n}\right) \cdot S_{O}^{-1}$. Likewise, the taxon $n$ is present in a fraction $\left(O_{n}\right.$ $\left.+O_{m+n}\right) \cdot S_{O^{-1}}$ of the stations sampled. This leads to the following equation of the expected number of stations of joint occurrence $\left(e_{m+n}\right)$ : $e_{m+n}=\left(O_{m}+O_{m+n}\right) \cdot S_{O}-1 \cdot\left(O_{n}+O_{m+n}\right)$. $S_{O}{ }^{-1} \cdot S_{O}$, or more simplified: $e_{m+n}=\left(O_{m}+\right.$ $\left.O_{m+n}\right)\left(O_{n}+O_{m+n}\right) \cdot S_{O^{-1}}$.

Since the value for $e_{m+n}$ is based on the observed values $O_{m}$ and $O_{n}$, the expected sample size per island will be $N_{e}=2 e_{m+n}+O_{m}+O_{n}$, and the number of scores to be used in the $\chi^{2}$ test will be $\Sigma N_{e}$. One of the requirements of the $\chi^{2}$ test is that $\Sigma N_{e}$ must sum up to the observed number of scores, $\Sigma N_{O}$. So, the frequencies for $e_{m+n}$, for $O_{m}$ and for $O_{n}$ should be adjusted to $\Sigma N_{O}$ by multiplication with a factor $\Sigma N_{O}$. $\Sigma N_{\ell}^{-1}$. The corrected expected frequencies are then: $E_{m+n}=\Sigma N_{O} \cdot \Sigma N_{\ell}^{-1} \cdot e_{m+n} ; E_{m}=\Sigma N_{O}$. $\Sigma N_{e}^{-1} \cdot O_{m}$, etc.

$\chi^{2}$ can now be computed as follows:

$\chi^{2}=\Sigma \frac{\left(2 O_{m+n}\right)^{2}}{2 E_{m+n}}+\Sigma \frac{O_{m}^{2}}{E_{m}}+\Sigma \frac{O_{n}^{2}}{E_{n}}-\Sigma N_{O}$

One of the inferences of the present test is that it should not be used if any of the expected frequencies is less than 5 (Meddis, 1975: 61). This rules out the use of this test for the majority of the islands sampled during our program. For the following islands, the solitary and joint occurrence of certain crustacean groups was testable:

Hadziids-cyclopids: Haiti-Curaçao-Aruba;

Hadziids-thermosbaenaceans: Haiti;

Thermosbaenaceans-cyclopids: Anegada-Tortola-Haiti.

\section{RESULTS}

\subsection{Hadziids and cyclopids}

During the present investigations, hadziid Amphipoda have been sampled in the following islands: Aruba, Curaçao, Bonaire, 
Tortuga, Marie-Galante, Guadeloupe, Barbuda, Antigua, St. Martin, Tintamarre, Anguilla, Puerto Rico, Haiti, and Jamaica. Although on almost all these islands Cyclopidae occur as well, most data could not be used for testing because of a variety of reasons: (1) On Bonaire and Tortuga only haline hadziids of the genus Saliweckelia are known, whereas for the present study we have used inland-water species only; (2) we have not sampled personally the island of Marie-Galante, and we are not sure that the sampling methods used there were identical with ours; (3) several islands have yielded insufficient "positive" stations, e.g. Antigua or Tintamarre, on which only 1 station yielded hadziids, although the number of stations sampled was large enough; (4) the computed "expected frequencies" for the test were lower than 5, making the use of the test risky.

As a result, only the Observed Frequencies $(O)$ for three islands (Aruba, Curaçao and Haiti) could be used for statistical treatment; these data are recorded in table I. At the bottom of this table, the Expected Frequencies $(e)$ and the Expected Frequencies after correction for $N$ (indicated by $E$ ) are introduced.

For $\Sigma N_{O}=272$ and $d f=3$, a $\chi^{2}$ value of 16.71 has been found, being significant at about the $0.1 \%$ level. It seems likely that the observation that hadziids and cyclopids do more often

Table I. Observed and expected frequencies of solitary and joint occurrence of hadziid Amphipoda (1) and cyclopid Copepoda (2) in three West Indian islands. For symbols: see text $\S 4$.

\begin{tabular}{|c|c|c|c|c|c|}
\hline & Haiti & Curaçao & Aruba & & \\
\hline$O_{1}$ & 22 & 62 & 13 & $\Sigma O_{1}$ & $=97$ \\
\hline $\mathrm{O}_{2}$ & 93 & 4 & 14 & $\Sigma \mathrm{O}_{2}$ & $=111$ \\
\hline$o_{1+2}$ & 24 & 6 & 2 & $\Sigma O_{1+2}$ & $=32$ \\
\hline$N_{O}$ & 163 & 78 & 31 & $\Sigma N_{O}$ & $=272$ \\
\hline$S_{o}$ & 139 & 72 & 29 & $\Sigma S_{o}$ & $=240$ \\
\hline$e_{1+2}$ & 38.72 & 9.94 & 8.27 & & \\
\hline$N_{e}$ & 192.44 & 85.88 & 43.54 & $\Sigma N_{e}$ & $=321.86$ \\
\hline$E_{1}$ & 18.59 & 52.40 & 10.99 & $\Sigma E_{1}$ & $=81.97$ \\
\hline$E_{2}$ & 78.59 & 3.38 & 11.83 & $\Sigma E_{2}$ & $=93.80$ \\
\hline$E_{1+2}$ & 32.72 & 8.40 & 6.99 & $\Sigma E_{1+2}$ & $=48.11$ \\
\hline
\end{tabular}

occur solitary than jointly, is not due to random fluctuations but to other effects.

\subsection{Hadziids and thermosbaenaceans}

The relevant data are summarized in table II, for the only island of which sufficient samples of both groups are available, Haiti.

For $\Sigma N_{O}=88$ and $d f=3$, a $\chi^{2}$ value of 8.92 has been computed, which is significant at better than the $5 \%$ level. It seems likely that the observed joint occurrence of hadziids and thermosbaenaceans deviates significantly from the occurrence to be expected if the taxa were not avoiding in some way each other's presence.

Table II. Observed and expected frequencies of solitary and joint occurrence of hadziid Amphipoda (1) and thermosbaenaceans (3) in Haiti. For symbols: see text $\S 4$.

$\begin{array}{lllr}O_{1} & 33 & e_{l+3} & 25.76 \\ O_{3} & 29 & N_{e} & 113.52 \\ O_{1+3} & 13 & E_{1} & 25.58 \\ N_{O} & 88 & E_{3} & 22.48 \\ S_{O} & 75 & E_{2+3} & 19.96\end{array}$

\subsection{Thermosbaenaceans and cyclopids}

In table III the relevant data for the solitary and joint occurrence of these groups on Anegada, Tortola, and Haiti are summarized.

For $\Sigma N_{O}=168$ and $d f=3$, a $\chi^{2}$ value of 0.77 has been computed, which is not significant. It must be concluded that the solitary occurrence of thermosbaenaceans and cyclopids, and their joint occurrence, do not deviate from random fluctuations.

\section{DISCUSSION}

\subsection{Ecological implications}

Apparently, hadziids and cyclopids are excluding each other to a significant extent, and so are hadziids and thermosbaenaceans. On the other hand, thermosbaenaceans and cyclopids occur jointly in the islands in a way not significantly different from random fluctuations. 
Table III. Observed and expected frequencies of solitary and joint occurrence of cyclopid Copepoda (2) and thermosbaenaceans (3) in three West Indian islands. For symbols: see text $\S 4$.

\begin{tabular}{lrrrll}
\multicolumn{7}{c}{ Anegada } & Tortola & Haiti \\
$O_{2}$ & 5 & 3 & 72 & $\Sigma O_{2}$ & $=80$ \\
$O_{3}$ & 1 & 5 & 6 & $\Sigma O_{3}$ & $=12$ \\
$O_{2+3}$ & 5 & 7 & 26 & $\Sigma O_{2+3}$ & $=38$ \\
$N_{O}$ & 16 & 22 & 130 & $\Sigma N_{O}$ & $=168$ \\
$S_{O}$ & 11 & 15 & 104 & $\Sigma S_{O}$ & $=130$ \\
& & & & & \\
$e_{2+3}$ & 5.45 & 8.00 & 30.15 & $\Sigma e_{2+3}=43.60$ \\
$N_{e}$ & 16.90 & 24.00 & 138.30 & $\Sigma N_{e}=179.20$ \\
$E_{2}$ & 4.69 & 2.81 & 67.50 & $\Sigma E_{2}=75.00$ \\
$E_{3}$ & .94 & 4.69 & 5.63 & $\Sigma E_{3}=11.26$ \\
$E_{2+3}$ & 5.11 & 7.50 & 28.27 & $\Sigma E_{2+3}=40.88$
\end{tabular}

A number of possibilities can be postulated to explain the fact that hadziids rarely occur simultaneously with cyclopids or thermosbaenaceans in the same sample:

(a) Certain abiotic factors determine the presence or absence of members of each taxon. The only factor in the groundwaters of these tropical, mostly calcareous islands, that shows a considerable range of values, is chlorinity. The waters examined during our program ranged from entirely fresh to polyhaline. For the purpose of this study, we compared the chlorinities of 40 localities with Thermosbaenacea, with those of 40 localities with hadziids (table IV). These comparisons have been made on the basis of chlorinity determinations from Haiti, being the only island on which hadziids and thermosbaenaceans coexist in numbers large enough to allow statistical treatment (as we have demonstrated above, this coexistence on the same island does not mean that they frequently coexist in the same locality).

Using a test for unrelated scores on two variables (one rankable, the chlorinities; the other nominal, the taxa), such as the MannWhitney test (Meddis, 1975, table 3.4.1 and $\S$ 5.5 ), we can compute a value for $Z=-0.66$, which is not significant.

In the same way, the chlorinities of 100 localities with cyclopids have been compared with 100 localities with hadziids (table V). Here too, only islands on which the taxa are known to occur both are used; these islands are listed at the top of the table. The Mann-Whitney test yields a value for $Z$ of 0.61 , which is likewise not significant.

Table IV. Chlorinities (in $\mathrm{mg} / \mathrm{1}, 0-10$ recorded as " 10 ", 11-20 recorded as " 20 ", etc.) in 40 samples of hadziid Amphipoda and 40 samples of Thermosbaenacea from Haiti.

Hadziids: 10, 10, 10, 20, 20, 20, 20, 20, 20, 20, 30, 30, 30, $30,30,40,40,40,50,50,50,50,50,60,70,80,80,90$, $110,130,140,150,190,190,200,240,310,450,3320$, 5640 .

Thermosbaenacea: 10, 20, 20, 20,20,20,20,20,20,30,30, $40,40,40,40,50,50,50,50,50,50,60,60,70,80,80$, $100,100,100,110,150,190,200,240,310,390,420,510$, $1640,2440$.

Table V. Chlorinities (in mg/l, 0-10 recorded as "10", 11-20 recorded as " 20 ", etc.) in 100 samples of hadziid Amphipoda and 100 samples of cyclopid Copepoda, from Guadeloupe, Antigua, Barbuda, St. Martin, Anguilla, St. Croix, Haiti, Curaçao and Aruba.

Hadziids: 10, 10, 20, 20, 30, 30, 90, 90, 130, 140, 140, 150, $160,180,190,190,200,200,200,210,220,230,240,240$, $270,290,290,290,290,290,300,320,330,380,390,410$, $410,470,470,480,550,580,590,600,660,660,680,690$, $690,690,710,710,800,830,890,910,920,950,1000$, $1040,1120,1240,1240,1250,1280,1280,1280,1310$, $1320,1400,1440,1460,1470,1480,1480,1580,1630$, $1640,1720,1760,1760,1800,1880,1880,2160,2500$, $2640,2800,2840,3100,3320,3600,4000,4160,4990$, $6280,8120,8250,8910,17820$.

Cyclopids: 10, 20, 20, 20, 20, 20, 30, 30, 40, 40, 40, 40, 50, $70,70,100,120,120,160,240,240,240,240,250,310$, $320,320,320,360,360,360,400,400,480,560,560,560$, $590,680,680,720,760,800,840,880,920,920,920,920$, $920,950,960,960,980,1000,1040,1040,1080,1080$, $1080,1160,1160,1280,1280,1280,1320,1320,1360$, $1360,1390,1400,1440,1480,1480,1480,1560,1640$, $1680,1720,1760,1760,1880,1880,1920,2000,2160$, $2280,2380,2630,2800,3320,3340,3600,3630,4000$, $4360,4900,4990,6280,9400$.

These tests make it likely that chlorinity is not the ecological (master) factor that determines the distribution of the three groups under study. A correlation between distribution and chlorinity was a priori rather unlikely, since in one and the same locality, the chlorinity 
fluctuates considerably during the year, in particular in the semi-arid islands, such as those of the Leeward Group, where periods of rains and droughts alternate, and with these the chlorinities drop and rise. Nevertheless, the faunal composition of a certain locality as a rule does not change during the year. (One most interesting exception is the groundwater of Blauw Baai Cave, Curaçao, in which marine or polyhaline stygobionts penetrate in dry periods, whereas limnic groundwater elements abound in periods of strong rains.)

Other abiotic factors, such as light penetration or temperature do not play any important role, since they are pretty constant in the groundwaters examined.

A number of possible biotic factors are discussed in paragraphs b-d.

(b) It is well known that cyclopids are quite abundant in surface waters. It could be postulated that they penetrate only occasionally in hypogean waters, which form the exclusive habitat for hadziids. The supposition that this would be a factor of importance in the observed avoidance of hadziids and cyclopids, is unlikely if one bears in mind that hadziids and thermosbaenaceans (both strictly hypogean taxa) avoid each other's presence likewise.

(c) Since cyclopids (length 1 to $3 \mathrm{~mm}$ ) and thermosbaenaceans (length 2 to $3 \mathrm{~mm}$ ) are considerably smaller than hadziids (length 3 to 8 $\mathrm{mm}$ ), the former may be limited to groundwater in microporous substrates, the latter to that of macroporous substrates. Although it is feasible that the larger hadziids will be absent from microporous substrates, it is improbable that cyclopids would avoid macroporous substrates. Moreover, it seems important to note that on islands where the hadziids are of small size (e.g., Curaçao; hadziid body size 3-4 mm-cf. Stock, 1977), the same absence of cyclopids in hadziid habitats is observed as in islands with large-sized hadziids.

(d) Hadziids interact with other Crustacea, such as thermosbaenaceans and cyclopids. In my opinion this is the only plausible explanation. As soon as hadziids are absent, the other two taxa show up. This is not only true for single localities, but also for entire islands (several islands in the Virgin group, such as Anegada, Tortola, St. John and Culebra, yielded dense populations of thermosbaenaceans but no hadziids; several islands of the Lesser Antilles, such as Aruba, Curaçao, Marie-Galante, Guadeloupe, Barbuda, St. Martin, Anguilla yielded an abundance of hadziids but no thermosbaenaceans).

What kind of interaction exists between hadziids and other small crustaceans is a matter of speculation. Food competition is highly unlikely, since supply of debris of higher plants, or of microscopical plants such as yeasts and fungi, is abundantly available in many wells and caves examined during our survey. Moreover, the mouthparts of the hadziids are of a quite different order of magnitude than those of the cyclopids, making different food requirements extremely likely.

The most plausible explanation is then, that hadziids feed on smaller Crustacea when these are available. In absence of crustaceans, the hadziids may turn to the usual food source for subterranean amphipods, viz. decaying leaves, fungi and yeast growing on loam in caves, eventually bat manure, etc.

\subsection{Zoogeographic implications}

The curious distribution of the Thermosbaenacea and the hadziid Amphipoda over the groundwaters of the West Indian islands can be explained in at least two entirely different ways: (1) by dispersal and vicariant events, and (2) by biological interactions.

6.2.1. Dispersal and vicariance. - The presence of Thermosbaenacea of the genus Monodella in the northeastern part of the Antillean arc (Cuba, Haiti, Puerto Rico, Culebra, and several of the British and U.S. Virgin Islands), may be interpreted as a good example of dispersal via a North American-Caribbean Track (see Rosen, 1976: 436 et seq., fig. 3). This idea is supported by the presence of a species of Monodella in several localities in Texas (Edwards Aquifer, see Stock \& Longley, 1981). 
The occurrence of Monodella on St. Croix, one of the U.S. Virgin Islands (Stock, 1976) seems somewhat puzzling at first glance, since St. Croix is separated from the remaining Virgin Islands by a stretch of very deep water, the Anegada Trough (length about $250 \mathrm{~km}$, maximum depth $4574 \mathrm{~m}$, see fig. 1). However, St. Croix appears to be a plate fragment of the Virgin Islands Bank, and "belongs, according to its geological structure, to the Virgin Islands, and not to the Lesser Antilles that start with Sombrero or Saba" (Weyl, 1966: 173, in translation). Mitchell, 1954, suggests that the Anegada Trough was formed relatively recently (Quarternary).

On the other hand, the presence of various Monodella species, closely related to the New World taxa, in the peri-Mediterranean belt, can very well be explained by sea-level drops in the later Tertiary (Fryer, 1965; Stock, 1976). During regressive movements of the sea level, marine interstitial populations of ancestral Monodella seem to have stranded and to have developed into continental groundwater inhabitants. At any rate, their actual localities are all found on or near the late-Tertiary Tethyan seaboards.

A similar "stranding" can easily be envisaged on the islands of the Antillean chain, which have undergone considerable positive vertical tectonic movements since the Miocene.

A difficult case is presented by the island of Anegada (British Virgin Islands), one of the islands on which Monodella abounds. This island has been connected with the others on the Puerto Rican Shelf by a land bridge until $10,000-8,000$ B.P., but the connections were flooded, and sometime between 8,000 and 6,000 B.P., Anegada drastically reduced in size by transgressive sea-level movements (Heatwole \& MacKenzie, 1967; Heatwole et al., 1981; for further references see Dunne \& Brown, 1976, 1979).

Since Anegada carries a rich groundwater population of Thermosbaenacea (genus Monodella), I take it for granted that the island never was inundated completely by seawater, and that the thermosbaenacean population dates from the time Anegada was interconnected with the other islands of the Puerto Rican Bank.

The other possibility, viz. that the thermosbaenaceans found nowadays on Anegada have "stranded" or "crawled out of the sea" recently (i.e. about 8000 years ago or less), is hard to accept, since no marine Monodella-like ancestor is actually known from the West Indies. So, a recent evolution of inland-water Monodella would require a second assumption, viz. the simultaneous extinction of its marine ancestor.

In the light of the relictary distribution of Monodella (and Thermosbaena) in the periMediterranean belt, I am inclined to attribute a similar age to the West Indian members of the genus, thus an origin during the final stages of the Tethys Sea, in the (late) Miocene epoch. The absence of Monodella on the many geologically younger islands of the Antillean arcs (e.g. the Volcanic Antilles, but in particular on young calcareous islands like Guadeloupe/Grande-Terre, Marie-Galante, Barbuda, Barbados, the Roques archipelago, etc.) becomes comprehensible then.

The distribution of the hadziids is more or less similar to that of the thermosbaenaceans, in terms of "generalized tracks". The group is virtually absent in South America (but for one species, found in a cave near the sea in Venezuela, Metaniphargus venezolanus Stock \& Botosaneanu, 1983), but is well represented in the northern half of Central America. Several species are known from the Edwards Aquifer in Texas.

In the eastern and southern parts of the periCaribbean area (Lesser Antilles, Leeward group, Venezuela) only a single genus, Metaniphargus, occurs in inland groundwaters, but in Central America, North America and in the Greater Antilles, quite a few genera are represented. If one wishes to speak of "tracks", a North American-Caribbean track is the most likely here as well.

In my personal opinion it is more likely that the hadziids, just like the thermosbaenaceans, originated from marine ancestors. Some of the 
older hadziid Amphipoda may be of similar age as the thermosbaenaceans (late Miocene). Several species must, however, have had a much more recent origin. For one of the subspecies of Metaniphargus curasavicus Stephensen, 1933, inhabiting exclusively the Pleistocene-Recent coastal plains of Curaçao, as well as for $M$. bullipes Stock, 1980 , from Marie-Galante and Metaniphargus n. sp. from Guadeloupe (islands that emerged less than 1 million years ago), a much more recent evolution from marine ancestors has been postulated (Stock, 1977, and Stock \& Vermeulen, in press).

Outside the West Indies, the presence of hadziids on certain young islands is known as well (e.g., Liagoceradocus acutus Andres, 1978, in lava tunnels of Lanzarote in the Canary Islands). These observations give support to the idea that some, if not most, hadziids belong to recently stranded waves that started to colonize the inland groundwaters.

Geologists do not agree as yet if the Greater Antilles were plate fragments once attached to a continental landmass (and/or to each other) or if they never had continental attachments. More agreement exists about the Lesser Antilles, of which no past attachments are assumed (Hedges, 1982).

Data based on the groundwater Malacostraca do not contradict a view that Jamaica has never been attached to any continental or insular landmass in the area, whereas Cuba, Hispaniola and the Puerto Rican plate might well have had mutual connections. If the origin of the earlier inland-water hadziids and thermosbaenaceans dates from the Miocene, it is plausible to infer that interconnections between the three islands still existed in that epoch.

I wish to illustrate the statements in the previous paragraph by the following observations:

The absence of Thermosbaenacea on Jamaica and the absence of a hadziid fauna that is diversified on generic level (only the periCaribbean genus Metaniphargus is present on the island; Stock, 1983), supports the interpretation of Hedges, 1982, that Jamaica has undergone a lateral movement in a direction opposite to that of Cuba and Hispaniola, along the Cayman Trough/Puerto Rico Trench fault system, which would not place Jamaica appreciably closer to any of the other Antilles.

The presence of Thermosbaenacea and a generically diversified hadziid fauna on Cuba, Hispaniola and Puerto Rico (fig. 1), might indicate that these islands have once been interconnected. Several possibilities, some of them as recently as the late Pliocene (ca. 5 million years) are tabulated by Hedges (1982, table I). Mitchell (1954) supposes that if the Puerto Rican bank ever was connected with Hispaniola, it lost the connection in the Pleistocene or earlier. Connections between the islands within the Puerto Rican bank have been extensive and recent; due to eustatic rises in sea level, these connections were lost only 8,000 to 10,000 years ago (Heatwole et al., 1981). The common possession of members of Monodella on several islands of the Puerto Rican Bank supports the recent existence of interconnections.

\subsubsection{Biological interactions. - It can} hardly be accidental that islands in which hadziids abound (such as Curaçao, Aruba, Barbuda, Anguilla, etc.) lack inland-water Thermosbaenacea, whereas islands in which Thermosbaenacea are abundant (such as Anegada, Virgin Gorda, Tortola, and Culebra) lack hadziids. The pattern might in part be due to interactions among members of these two groups.

Since thermosbaenaceans are generally considered "primitive" crustaceans ("living fossils" in the words of Botosaneanu \& Delamare Deboutteville, 1967), it is tempting to assume that they were once - in the older Caenozoic - more widely distributed over the West Indian islands. Fryer (1965) made it probable that the peri-Mediterranean Thermosbaenacea evolved from marine ancestors that "stranded" during geotectonic oscillations in the late Miocene. Stock (1977) thought it not unlikely that the hadziids descended, likewise from marine ancestors, from Miocene, Pliocene or Pleistocene strandings. The presence of had- 
ziids on islands that emerged relatively recently (Lanzarote, Grande-Terre, Marie-Galante) gives further support to the idea that some, if not most, hadziids belong to younger waves that started to colonize the inland groundwaters.

In the West Indies, the nonmarine Thermosbaenacea are restricted to chlorinities of 10 to $2440 \mathrm{mg} / \mathrm{l}$ (limnic and oligohaline waters according to the Venice System). Hadziids are, at least on the islands where thermosbaenaceans occur as well, distributed predominantly in waters of the same chlorinity, and do not show a significant overall difference in salinity preference. If we consider, however, the distribution of the hadziids over all the islands in the West Indies, including those that do not harbour thermosbaenaceans, we find that over $15 \%$ of the hadziid stations have higher salinities than in any thermosbaenacean locality. Eleven percent of the hadziid stations classifies as mesohaline, and one percent even as polyhaline. This halophily may be taken as an indication for a more recent descent from marine ancestors for the hadziids, in comparison to the more halofugous thermosbaenaceans.

When the hadziids evolved in the inland groundwaters, they started to predate on the older inhabitants and finally exterminated weaker animals, such as thermosbaenaceans. It is rather important in my view that almost every calcareous island of the southern, eastern and northeastern part of the Antillean arc possesses groundwater hadziids, often in high population densities, but lacks thermosbaenaceans. Of the four islands that show joint occurrence of both groups, one (St. Croix) has a low population density of hadziids, and the other three (Cuba, Hispaniola and Puerto Rico) are at the same time the three largest islands of the Antilles. The larger island size is presumably correlated with a more varied array of ecological habitats and a reduction of competition, thereby preventing the thermosbaenaceans from total extermination.

\subsubsection{Conclusions. - Every process de-}

scribed above (dispersal, vicariance, biological interactions) is supported by at least some evidence. Presumably, the actual pattern of insular occurrence and intrainsular distribution is based on a complicated combined action, not necessarily during the same geological epoch, of the various processes. In the case of groundwater organisms such as thermosbaenaceans and hadziids, the following evolutionary scenario is not contradicted by any fact:

(1) origin of the Monodella group from marine ancestors by stranding (vicariant process, called regression model);

(2) adaptation to inland-water conditions;

(3) dispersal over emerged plates (e.g., the Puerto Rican plate), eventually over adjacent plates (e.g., Cuba/Hispaniola);

(4) stranding of more recent waves of marine descendants (hadziids);

(5) adaptation of the new invaders to inlandwater conditions, followed by dispersal;

(6) extermination by predation of the older groundwater Crustacea (thermosbaenaceans) by the younger ones (hadziids);

(7) survival of thermosbaenaceans in islands without hadziids and in large islands offering a greater number of habitats allowing the predated groups to find a refuge.

\section{REFERENCES}

Andres, H. G., 1978. Liagoceradocus acutus sp. n., ein Gammaride aus der Jameos del Agua auf Lanzarote (Amphipoda, Crustacea). Mitt. hamb. zool. Mus. Inst., 75: 249-253.

Barnard, J. L. \& G. S. Karaman, 1982. Classificatory revisions in gammaridean Amphipoda (Crustacea), part 2. Proc. biol. Soc. Wash., 95 (1): 167-187.

Botosaneanu, L., V. Decou \& Şt. Negrea, 1973. La situation des matériaux zoologiques recueillis en 1969 et 1970 par les missions cubano-roumaines à Cuba. Rés. Expéd. biospéol. cubano-roum. Cuba, 1: 13-18.

Botosaneanu, L. \& Cl. Delamare Deboutteville, 1967. Fossiles vivantes des eaux souterraines. Sciences (Paris), 52: 17-22.

Bou, V., 1975. Les méthodes de récolte dans les eaux souterraines interstitielles. Annls. Spéléol., 29 (4): 611-619.

Bousfield, E. L., 1977. A new look at the systematics of gammaroidean amphipods of the world. Crustaceana, Suppl. 4: 282-316. 
Dancau, D., 1973. Contribution à la connaissance des Amphipodes souterrains de Cuba. Rés. Expéd. biospéol. cubano-roum. Cuba, 1: 223-229.

Dunne, R. P. \& B. E. Brown, 1976. Anegada marine biological survey. Report of the Cambridge Anegada Expedition 1975: i, 1-138.

-_ ——, 1979. Anegada. Atoll Res. Bull., 236: 1-84.

Fryer, G., 1965. Studies on the functional morphology and feeding mechanism of Monodella argentarii Stella (Crustacea: Thermosbaenacea). Trans. R. Soc. Edinb., 66 (4): 49-90.

Heatwole, H. \& F. MacKenzie, 1967. Herpetogeography of Puerto Rico, IV. Evolution, 21: 429-438.

Heatwole, H., R. Levins \& M. D. Byer, 1981. Biogeography of the Puerto Rican Bank. Atoll Res. Bull., 251: 1-62.

Hedges, S. B., 1982. Caribbean biogeography: implications of recent plate tectonic studies. Syst. Zool., 31 (4): 518-524.

Holsinger, J. R., 1977. Some observations on the taxonomy of the Cuban subterranean amphipod genus Weckelia (Gammaridae). Rés. Expéd. biospéol. cubano-roum. Cuba, 2: 267-269.

Mendis, R., 1975. Statistical handbook for non-statisticians: i-viii, 1-162 (McGraw-Hill, Maidenhead, U.K.).

Mitchell, R. C., 1954. A survey of the geology of Puerto Rico. Univ. Pto. Rico agric. expl. Sta. techn. Pap., 13: $1-167$.

Mittelberg, H. H., 1980. A collapsible phreatobiological pump for sampling narrow drill-holes. Stygo News, 3 (1): 10-12.

Orghidan, T. N., 1973. Stations hypogés et épigés prospectées à Cuba entre les 3 novembre et 12 décembre 1970. Rés. Expéd. biospéol. cubano-roum. Cuba, 1: 45-51.
Rosen, D. E., 1976. A vicariance model of Caribbean biogeography. Syst. Zool., 24 (4): 431-464.

Stock, J. H., 1976. A new genus and two new species of the crustacean order Thermosbaenacea from the West Indies. Bijdr. Dierk., 46 (1): 47-70.

- , 1977. The taxonomy and zoogeography of the hadziid Amphipoda, with emphasis on the West Indian taxa. Stud. Fauna Curaçao, 55 (177): 1-130.

- - 1980. Un Metaniphargus (Amphipoda) nouveau de l'île Marie-Galante (Antilles). Bull. Mus. natn. Hist. nat. Paris, (4) (2) (Sect. A, no. 2): 413-419.

,-- 1982 . The influence of hadziid Amphipoda on the occurrence and distribution of Thermosbaenacea and cyclopoid Copepoda in the West Indies. Pol. Arch. Hydrobiol., 29 (2): 275-282.

- 1983 . The stygobiont Amphipoda of Jamaica. Bijdr. Dierk., 54 (2): 267-286.

- , in press. Amphipoda - Melitid grouping. In: L. Botosaneanu ed., Stygofauna mundi (E. J. Brill, Leiden).

Stock, J. H. \& L. Botosaneanu, 1983. Première découverte d'Amphipodes Gammaridae du groupement des hadziides dans des eaux souterraines de l'Amérique du Sud: description de Metaniphargus venezolanus sp. n. Bijdr. Dierk., 53 (1): 158-164.

Stock, J. H. \& G. Longley, 1981. The generic status and distribution of Monodella texana Maguire, the only known North American thermosbaenacean. Proc. biol. Soc. Wash., 94 (2): 569-578.

Stock, J. H. \& J. J. Vermeulen, in press. Crustacés Amphipodes stygobies de la Guadeloupe en relation avec l'histoire géologique de l'île. Mém. Biospéol.

[Venice System], 1959. The Venice system for the classification of marine waters according to salinity. Symposium on the classification of brackish waters, Venezia 8-14 Aprile 1958. Archo. Oceanogr. Limnol., 11 (Suppl.): 243-245.

Weyl, R., 1966. Geologie der Antillen. Beitr. region. Geol. Erde, 4: i-viii, 1-410 (Borntraeger, Berlin). 